\title{
Active Management of Plant Canopy Temperature as a Tool for Modifying Plant Metabolic Activity
}

\author{
James R. Mahan, John J. Burke \\ USDA/ARS, Plant Stress and Water Conservation Laboratory, Lubbock, Texas, USA \\ Email: james.mahan@ars.usda.gov
}

Received 5 January 2015; accepted 23 January 2015; published 26 January 2015

Copyright (C) 2015 by authors and Scientific Research Publishing Inc.

This work is licensed under the Creative Commons Attribution International License (CC BY). http://creativecommons.org/licenses/by/4.0/

(c) (i) Open Access

\section{Abstract}

The relationship between a plant and its thermal environment is a major determiner of its growth and development. Since plants grow and develop within continuously variable thermal environments, they are subjected to continuous thermal variation over their life cycle. Transpiration serves to uncouple the temperature of the plant from that of its environment in a manner that reduces the occurrence of high temperature stresses that can limit plant performance. In some agriculturally important plants, there are desirable metabolic outcomes that are associated with specific stress events (e.g. wine grapes). In these plants it is often desirable to induce temperature and water stresses of known magnitude and duration at specific points in the growing season. In this study we used a computer-controlled irrigation system that used cotton canopy temperature to control irrigation in greenhouse-grown plants over a 10-day period. The system was designed to irrigate in a manner that altered the canopy temperature relative to specific temperature thresholds $\left(28^{\circ} \mathrm{C}, 30^{\circ} \mathrm{C}, 32^{\circ} \mathrm{C}\right.$ and $\left.34^{\circ} \mathrm{C}\right)$. The results demonstrate that automated irrigation management based on canopy temperature is capable of altering the temporal pattern of canopy temperature in a desired manner using a feed-back loop. Potential limitations on this action are related to the range of air temperatures, radiation and humidity within the environment.

\section{Keywords}

Irrigation, Optimum Temperature, Canopy Temperature

\section{Introduction}

Plants, as sedentary poikilotherms, are subject to thermal variation. Environmental temperatures vary according 
to both diurnal and seasonal patterns. The thermal environment of many temperate plants is bounded by lethally low temperatures that define their growing seasons. Within the non-lethal thermal range, the plant is subjected to a continuously variable thermal environment. Temperature plays an important role in the plant environment interactions and is perhaps one of the most pervasive effectors of plant growth and development. The relationships between organisms and their thermal environments have been thoroughly summarized by Hochachka and Somero [1].

Biochemical reactions are, by nature, thermally dependant, with reaction rates being relatively sensitive to temperature. Given that the temperature of a plant is related to that of its environment, and that the thermal environment is constantly variable, the rates of the biochemical reactions of the plant are continuously affected by temperature in a potentially complex manner. Plant temperatures can be broadly classified with respect to some aspect of plant function as below optimal, optimal, and above optimal. On a cellular level, low temperatures can result in loss of membrane integrity. Temperatures can be too low to provide adequate night respiration for plant maintenance or too high for photosynthetic assimilation. Fruit ripening can be retarded or accelerated in response to temperature. Thus the concept of metabolic optimality, while perhaps obvious in principle, can become complex with respect to which indictor of optimality is being assessed.

The relationship between plant temperature and environmental temperature is potentially rather complex. In the literature, plant temperature is often assumed to be similar to the air temperature though it is generally acknowledged that under water deficits the temperature of the plant can be higher than that of the air. Non-contact thermal measurements using infrared thermometers have become increasingly common with advances in the field. Lower cost infrared thermometers are now available for use in production agricultural settings [2] and crop temperatures are routinely measured on seasonal time scales in production settings.

When an organism is subject to thermal variation, the rate of enzyme reactions and the resultant metabolism, will vary continuously. It has been demonstrated that the thermal dependence of the kinetics of enzymes can be used to define optimal temperatures of plants [3]-[5]. Irrigation management based upon thermal optima defined in terms of enzyme kinetic properties has proven to optimize production in several cropping systems [6]. Kinetic properties of enzymes responsible for herbicide activity have been used to explain thermal dependency of some aspects of herbicide efficacy [4] [5]. They used this approach to define optimal thermal ranges for herbicide efficacy. The thermal dependence of kinetics of malate synthase from cotton was used to develop a model that predicted cotton emergence under thermal variation [7].

In an agricultural crop, optimality can be defined anthropomorphically in terms of the agronomic purpose of the desired product. Issues of yield and quality are central to agronomic optimality. For example, in a forage crop, total seasonal biomass may be the optimal outcome while, in an oilseed crop, the yield and quality of the oil may be used to define an optimal outcome. For a fiber crop such as cotton, biomass is of value only to the extent to which it is related to fiber yield and quality and fully optimized vegetative growth is undesirable as it is associated with reduced harvest index and negative fiber characteristics.

Irrigation based upon canopy temperature measurements is capable of altering the relationship between the plant's thermal environment and the temperature of the plant canopy. In the most general sense, as plant water use increases, canopy temperature decreases and canopy temperatures of plants experiencing water deficits aregenerally elevated relative to those that are well-watered. Irrigation management designed to prevent water deficit stress is a common approach for many cropping systems. In these instances irrigation is applied to fully provide water over the course of a growing season in order to maximize yield. While the stress prevention approach is widely appreciated, there are agricultural systems in which the controlled imposition of water deficits can have desirable effects.

Thus there are agronomically desirable outcomes of plant water and thermal stresses. The next few paragraphs will describe some examples of agriculturally important plants for which agronomic optimality can be associated with water and temperature stresses.

Alfalfa responds morphologically to drought stress with decreases in stem number, stem elongation, and yield. The quality of alfalfa forage produced under drought conditions is often higher than that of the well-watered fields. Halim et al. [8] concluded that forage quality of alfalfa increased when plants were grown under continuous water stress. They attributed at least part of the response to changes in the leaf to stem ratio with a contribution from systematic decrease in cell wall content and increased crude protein content in response to water deficits. Shock et al. [9] reported optimal alfalfa seed production at 50\% ET replacement with a balance among seed yield, seed viability and seed weight. Penny packer et al. [10] reported drought stress could reduce disease 
symptoms in alfalfa. Carter and Sheaffer [11] reported that controlled water deficits could significantly improve the water use efficiency of alfalfa production.

Beneficial effects of water stress in grapes are well known [12]. An early response of grapevines to water stress is a reduction in vegetative growth that serves to maintain the availability of nutrients and metabolites to the fruit. Water deficits have been shown to reduce the size of the grape berries and result in an increase in the ratio of skin to fruit volume that can improve the quality of the grape [13]. Extreme water deficits can negatively affect vine survival and actually produce anti-quality factors. Thus while moderate and controlled water deficits can have positive effects on grape production, the magnitude of the stress must be controlled and monitored to avoid harmful stresses [14]. Olive yield is related to increased irrigation while oil quality is enhanced by water deficits [15]. Moriana et al. [16] postulated that there is a need for improved water monitoring/management tools for olive orchards. Management of water deficits in olive orchards as been successful [17] [18] though improvement is still warranted.

\section{Materials and Methods}

\subsection{Study Period}

The study was carried out over a 10-day interval from 4 March to 13 March 2013 in a greenhouse in Lubbock, TX.

\subsection{Greenhouse Thermal Control}

The air temperature of the greenhouse was controlled by a combination of steam heating and cooling provided by fans to circulate outside air when air temperatures exceeded the upper thermal limit. The upper thermal limit was set to $45^{\circ} \mathrm{C}$ with the lower limit set to $20^{\circ} \mathrm{C}$. The 5-minute pattern of air temperature and solar radiation in the greenhouse over the 10-day experimental interval are shown in Figure 1. The air temperature varied from a low of $25^{\circ} \mathrm{C}$ to a high of $40^{\circ} \mathrm{C}$. Radiation values were typical for early March.

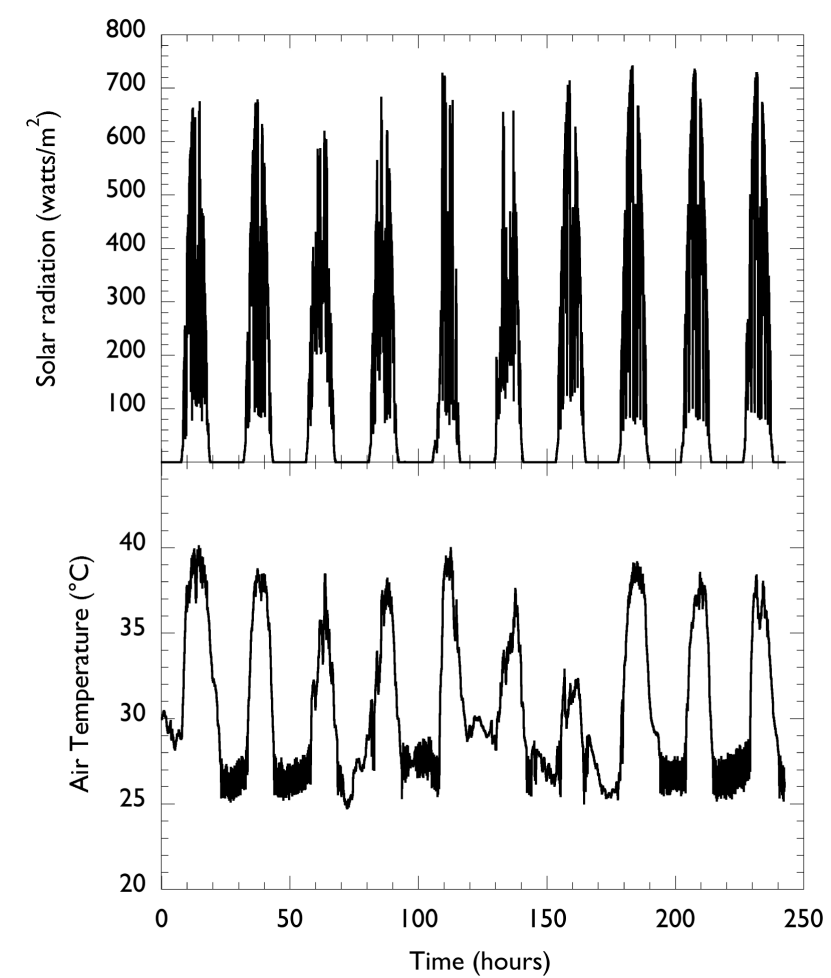

Figure 1. Air temperature and solar radiation measured in the glasshouse over the course of the 10-day (240-hour) study. Both parameters were measured at $2 \mathrm{~m}$ above ground level. 


\subsection{Cotton Culture}

Fibermax 9180 cotton (G. hirsutum) was planted in 8-liter pots in a potting mixture of sand and peat. Pots were maintained under full drip irrigation and nutrition until the canopy was sufficient for canopy temperature monitoring. When cotton plants had produced fully expanded leaves and a height of $40 \mathrm{~cm}$ the canopy was sufficient for thermal monitoring.

\subsection{Greenhouse Canopy Temperature Monitoring}

Plant temperatures were monitored with Smartcrop IR sensors (Smartfield Inc Lubbock, TX). Canopy temperature for each plant was recorded on a 1-minute interval by an IRT sensor that was positioned at a distance of approximately $5 \mathrm{~cm}$ from a fully expanded leaf at the top of the canopy. The position of the sensor was adjusted 2 times each day.

\subsection{Canopy Temperature-Based Irrigation Control}

Irrigation management was achieved through a microprocessor controlled drip irrigation system. The system consisted of a manifold header water line with a series of solenoid-actuated valves to control the application of water to individual pots. A distribution line directed water from the solenoid valves to an emitter for each plant. Irrigation decisions were made on a 5-minute interval based on the mean of the average of the preceding fiveminute measures of canopy temperature. Irrigation events were initiated based upon the average canopy temperature of the plants during the 5-minute irrigation interval.

\subsection{Temperature Thresholds as Irrigation Control Parameters}

In this study irrigation was managed in response to the occurrence of canopy temperatures that were above a series of temperature thresholds. Canopy temperature thresholds, derived from the thermal characteristics of cotton, were used to make irrigation decisions on the basis of the 5-minute means of canopy temperature. Previous studies for the relationships among canopy temperature, plant metabolism and irrigation indicate that $28^{\circ} \mathrm{C}$ is a useful estimate of the optimal temperature for several aspects of cotton physiological processes. The temperature thresholds chosen for the irrigation management were $28^{\circ} \mathrm{C}$ (TT28), $30^{\circ} \mathrm{C}$ (TT30), $32^{\circ} \mathrm{C}$ (TT32) and $34^{\circ} \mathrm{C}$ (TT34). For each plant in the system, the 5-minute mean of canopy temperature was compared to the temperature threshold for the pot. If the canopy temperature exceeded the threshold, the pot was irrigated. If the canopy temperature was below the threshold there was no irrigation for that 5-minute period. The cycle of decision, irrigation, and decision was repeated every 5 minutes throughout each day over the course of multiple days. This protocol produced a variable pattern of irrigation events that resulted in different distributions of canopy temperature over the irrigation period.

\section{Results}

\subsection{Irrigation}

The irrigation system applied $30 \mathrm{ml}$ of water for each irrigation event. The total irrigation volume is directly related to the number of irrigation events. Table 1 shows the water applied during the 10-day control period. Based on the standard irrigation protocol for the greenhouse, the volume of water applied during the 10-day in-

Table 1. Irrigation summary for the 10-day study period in 4 temperature threshold irrigation treatments in cotton.

\begin{tabular}{ccccc}
\hline Parameter & TT2 $8^{\circ} \mathrm{C}$ & $\mathrm{TT}^{\circ} 0^{\circ} \mathrm{C}$ & $\mathrm{TT}^{\circ} 2^{\circ} \mathrm{C}$ & $\mathrm{TT} 34^{\circ} \mathrm{C}$ \\
\hline Water applied in control irrigation method (liters) & 20 & 20 & 20 & 20 \\
Number of irrigation events & 461 & 385 & 237 & 192 \\
Irrigation volume for TT (liters) & 13.8 & 11.6 & 7.1 & 5.8 \\
TT irrigation as fraction of fixed irrigation & 0.69 & 0.58 & 0.36 & 0.29 \\
Irrigation as a fraction of TT28 ${ }^{\circ} \mathrm{C}$ (full irrigation) & 1 & 0.83 & 0.51 & 0.41 \\
\hline
\end{tabular}


terval would have been $20 \mathrm{~L}$. The relationship between the irrigation thresholds and the irrigation volume applied is shown in Figure 2. Irrigation controlled by the canopy temperature stress management system resulted in the application of less water than would be applied over the same period using the standard fixed-volume application at a set time interval. The TT2 $8^{\circ} \mathrm{C}$ treatment applied approximately $30 \%$ less water than the fixed irrigation while producing a plant that was effectively fully irrigated. As the TT was increased the fraction of water applied decreased relative to the fixed irrigation protocol. When compared to the TT28 ${ }^{\circ} \mathrm{C}$ treatment, the different TT treatments received from $83 \%$ to $41 \%$ of full irrigation.

\subsection{Analysis of Air and Canopy Temperature}

In the preceding sections it has been established that irrigation management based on the canopy temperature stress management system resulted differential irrigation that produced varying levels of water stress in cotton over the 10-day study period. The following analysis will focus on the patterns of air and canopy temperature that are associated with the various TT irrigation treatments.

\subsection{Potential Control Time}

In the broad sense the goal of this study was to investigate the extent to which plant water and temperature stress could be managed using canopy temperature and irrigation. The questions are: 1) to what extent can canopy temperature be controlled? and 2) how much can canopy temperature be altered through irrigation? The ability to manage stress through canopy temperature monitoring was always limited by the amount of time during which the temperature of the plant is related to transpiration, and by extension to plant water status. Canopy temperature cannot be used to manage water stress during periods when canopy temperature is not related to plant transpiration. Thus the first task in the assessment of the control method is to estimate the extent of control that is possible within a given environment. During night-time hours the temperature of the canopy is often close to that of the surrounding air and not particularly indicative of the water status of the plant. Thus the analysis of canopy temperature and irrigation in this study has been limited to daylight hours by excluding time when radiation was less than or equal to 0. Applying the radiation filter removed 126 hours from the 240-hour study period resulting a 114-hour daytime period for analysis.

During the daylight hours, the ability to manage canopy temperature relative to a desired temperature threshold through irrigation will largely be determined by the threshold temperature and the air temperature. For a given temperature threshold value, irrigation control by this protocol is generally limited to periods when the temperature of the air is equal to or greater than the temperature threshold. The number of hours when Tair $\geq$ temperature threshold represents the potential control time for irrigation-based stress management for each TT value. The potential control times for the temperature thresholds in the study are; TT28 $=101 \mathrm{~h}$, TT30 $=92.5 \mathrm{~h}$, TT32 $=76 \mathrm{~h}$, and TT34 $=59 \mathrm{~h}$. Over the 114-hour daylight period $(\mathrm{rad}>0)$, the daylight periods when Ta $\geq \mathrm{TT}$ for a given temperature threshold, the potential control time that irrigation could have been used to manage wa-

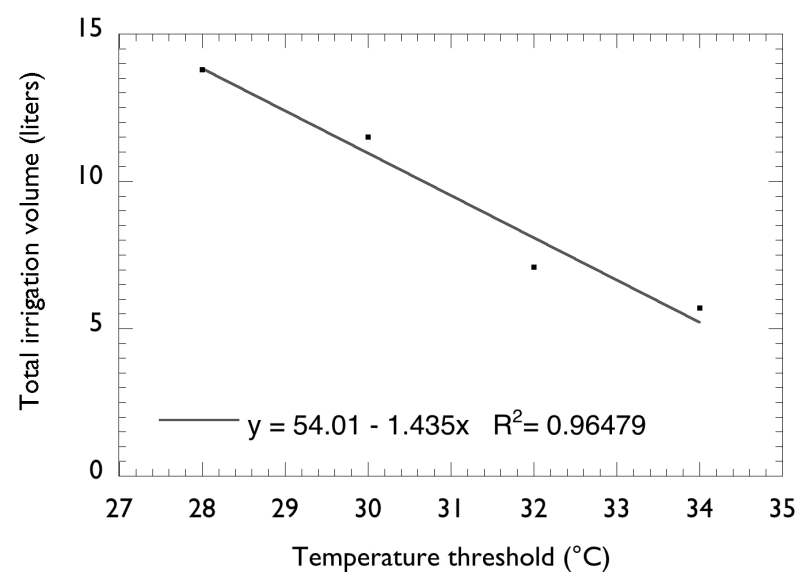

Figure 2. Total irrigation volume (liters) applied over the 10-day period for each of 4 irrigation temperature thresholds. 
ter stress are; TT28 = 88\%, TT30 = 81\%, TT32 =66\%, and TT34 $=52 \%$. As the temperature threshold increased, the potential control time for stress management decreased. Thus the potential extent of stress management is a function of the radiation environment, the thermal environment, and the desired temperature threshold.

Figure 3 shows the canopy temperature for the $28^{\circ} \mathrm{C}$ and the air temperature over the 10-day study period. The figure indicates the inherent difficulties of the visual analysis of such time-course data in line graphs in that only 1 of 10 temperature sensors in the study is shown. Since the intent of the irrigation method was to alter the distribution of temperatures based on temperature thresholds, the data was binned to provide information on the temperature distribution

Air and canopy temperature data were binned at $1^{\circ}$ intervals from $20^{\circ}$ to $50^{\circ}$. Figure 4 shows the distribution of canopy temperature and air temperature for each of the irrigation time thresholds.

\subsection{Irrigation Reproducibility}

In each panel the distribution of canopy temperatures for either 2 or 3 replicates in each of the TT irrigation treatments is compared to the air temperature. Each of the replicates represents canopy temperatures collected over the 10-day period for individual plants in different pots at different positions on the greenhouse bench. Canopy temperature was measured by a single IRT sensor and the irrigation was controlled using the canopy temperature data and a TT by an irrigation valve unique to that pot. The distribution of canopy temperatures among the replicated pots was similar over the 10-day period. This indicates that the TT irrigation protocol altered canopy temperatures in a reproducible manner time.

\subsection{Irrigation-Protocol and the Distribution of Canopy Temperatures}

The irrigation control system was designed to irrigate in response to specific canopy temperature threshold values with the intended effect of a reduction in the occurrence of canopy temperatures above the TT. Such a controlled change in the distribution of canopy temperatures will allow the imposition of targeted plant water deficits.

The canopy temperature analysis is focused on 2 criteria, 1 -the extent to which the canopy temperatures were altered and 2-the extent to which the alteration of canopy temperatures could be controlled to specific thermal ranges. Temperature measurements in biological systems are most useful when they are compared to a temperature standard. To that end, the distributions of canopy temperatures in the TT-based irrigation regimes were compared to the following "standards"; air temperature, temperature threshold values, and to a temperature of $28^{\circ} \mathrm{C}$ which is an estimate of the thermal optimum of cotton (refs) and an indicator physiological stress.

\subsection{Comparisons of Canopy Temperatures to Air Temperature}

Over the 10-day period, the irrigation protocol altered canopy temperature with respect to air temperature with a mean air temperature $=32.2^{\circ} \mathrm{C}$ and mean canopy temperatures in the irrigation treatments of; $25.8^{\circ}$ for TT28,

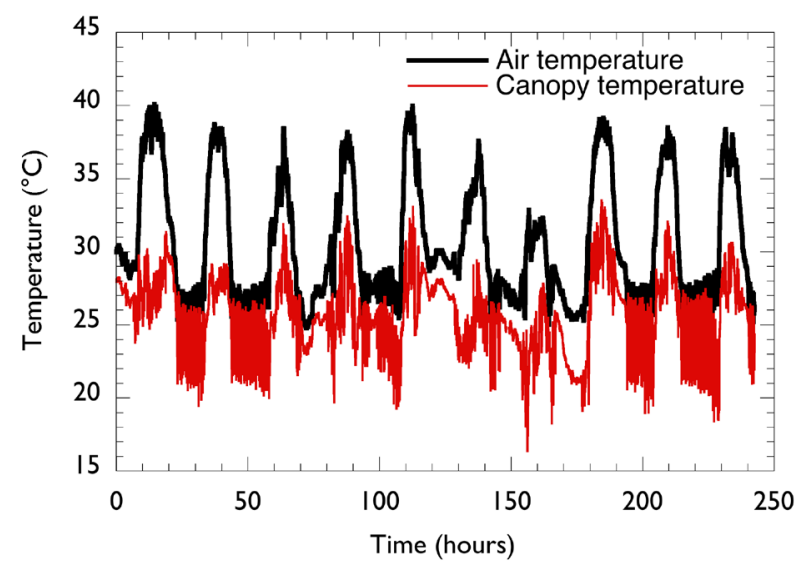

Figure 3. Canopy temperature for the $28^{\circ} \mathrm{C}$ TT and air temperature over the 10-day (240-hour) experimental period. 


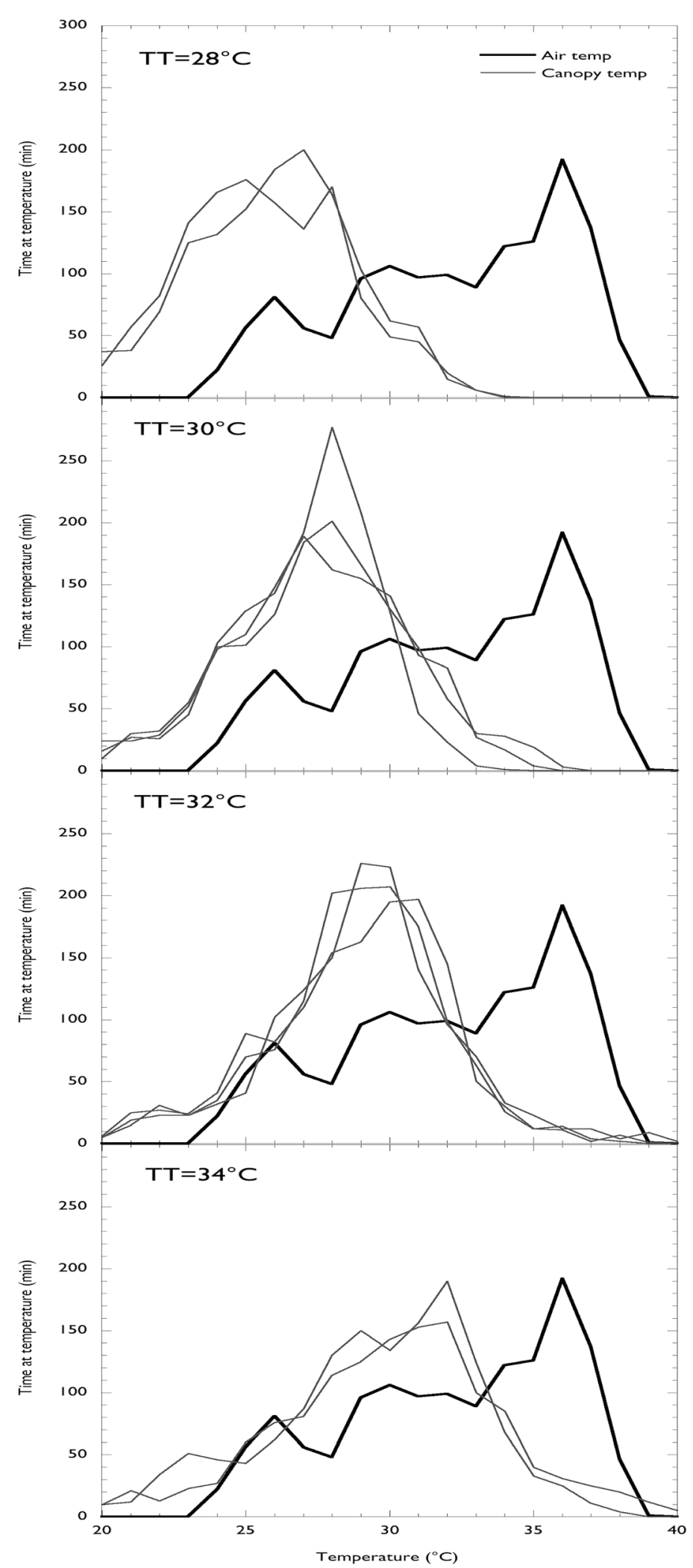

Figure 4. The distribution of air and canopy temperatures over the 10-day (240-hour) experimental period. The 5-min temperature values were binned at $1^{\circ} \mathrm{C}$ icrements from $20^{\circ} \mathrm{C}$ to $5^{\circ} \mathrm{C}$. The total minutes at each temperature over the 10-day interval is shown on the $y$-axis. 
$27.4^{\circ}$ for TT30, $28.9^{\circ}$ for TT32, and $29.9^{\circ}$ for TT34. Thus for each time threshold irrigation treatment, transpiration reduced the canopy temperatures compared to the air temperature.

Each temperature distribution curve is characterized by a peak (Figure 5). The peak in distribution of air temperatures was $36^{\circ} \mathrm{C}$. The peak values in the distributions of canopy temperature were affected by the TT irrigation management as follows; TT28 $=26^{\circ} \mathrm{C}$, TT30 $=28^{\circ} \mathrm{C}$, TT32 $=30^{\circ} \mathrm{C}$, and TT34 $=32^{\circ} \mathrm{C}$. In each TT irrigation treatment, the peak in the canopy temperature distribution was $2^{\circ}$ less than the corresponding temperature threshold value.

\subsection{Comparisons of Canopy Temperatures to Temperature Thresholds}

The distribution of the canopy temperature for each TT irrigation was assessed in terms of a temperature range of TT $\pm 1{ }^{\circ} \mathrm{C}$. The distribution of air temperatures range defined at $\mathrm{TT} \pm 1^{\circ} \mathrm{C}$ varied with the TT value: TT28 = $15 \mathrm{~h}$, TT30 $=21 \mathrm{~h}$, TT32 $=25 \mathrm{~h}$, and TT34 $=29 \mathrm{~h}$. The irrigation treatments altered the time that canopy temperature was in the range TT $\pm 1^{\circ} \mathrm{C}$ varied; TT28 $=39 \mathrm{~h}$, TT30 $=32$, TT32 $=33 \mathrm{~h}$, and TT34 $=19 \mathrm{~h}$. Out of the114 hours that thermal control was possible $(\mathrm{Ta}>\mathrm{TT})$, the time within the TT $\pm 1^{\circ}$ windows for each TT value was: TT28 $=39 \%$, TT30 $=35 \%$, TT32 $=43 \%$, and TT34 $=32 \%$. In this regard the method was able to shift canopy temperatures toward specific thermal ranges.

\subsection{Comparisons of Canopy Temperatures to Cotton Optimal Temperature}

The distribution of canopy temperatures resulting from the TT irrigation treatments was assessed relative to $28^{\circ} \mathrm{C}$, the optimal temperature for cotton metabolism. Out of the 96 hours that thermal control to $28^{\circ} \mathrm{C}$ was possible $\left(\mathrm{Ta}>28^{\circ} \mathrm{C}\right)$, the time within the $28^{\circ} \mathrm{C} \pm 1^{\circ} \mathrm{C}$ windows for each TT value was: $\mathrm{TT} 28=37 \%$, TT30 $=$ $50 \%$, TT32 $=42 \%$, and TT34 $=30 \%$. The TT irrigation altered the fraction of time that canopy temperature was metabolically optimal, thus providing a means for increasing time that canopy temperature is optimal.

An example, let us suppose that we have a metabolic outcome that is associated with a canopy temperature between $32^{\circ} \mathrm{C}$ and $35^{\circ} \mathrm{C}$ during a specific period in the development of a plant. Our management goal is to create a series of water deficits ranging from full irrigation to some stress level and then back to the fully irrigated state. The sequence of panels in Figure 6 shows what we propose as a possible implementation of the TT management protocol with; a-a period at fully irrigated $\left(\mathrm{TT} 28^{\circ} \mathrm{C}\right), \mathrm{b}-\mathrm{a}$ following period of low stress at thermal optimum $\left(\mathrm{TT} 30^{\circ} \mathrm{C}\right), \mathrm{c}$ - a period of high stress $\left(\mathrm{TT} 34^{\circ} \mathrm{C}\right), \mathrm{d}$-increased irrigation to moderate stress $\left(\mathrm{TT} 32^{\circ} \mathrm{C}\right.$ and $\mathrm{e}-\mathrm{a}$ return to full irrigation $\left(\mathrm{TT} 28^{\circ} \mathrm{C}\right)$.

\section{Discussion}

The goal of the study was to manage water deficits in plants through automated irrigation management. Management of water deficits requires an ability to establish and maintain a balance between transpiration and irri-

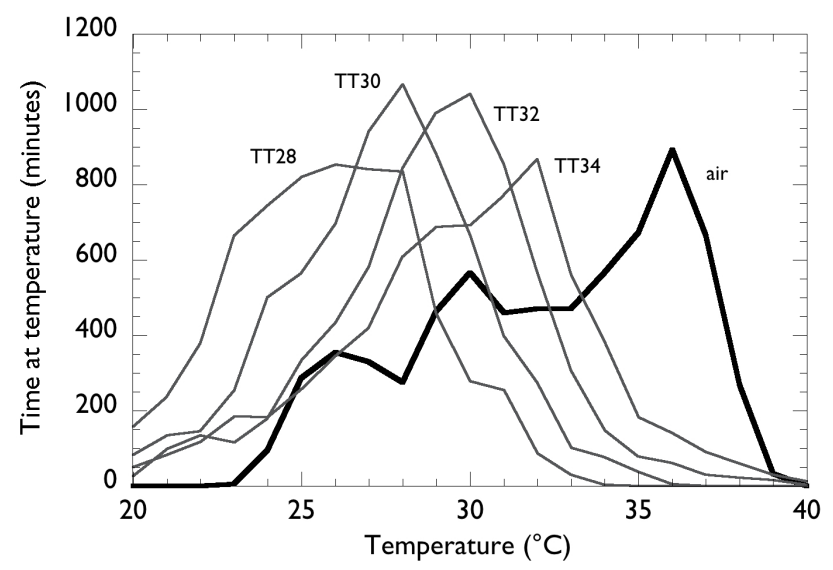

Figure 5. Temperature was measured on 5-minute intervals. The 5-min temperature values were binned at $1^{\circ} \mathrm{C}$ increments from $20^{\circ} \mathrm{C}$ to $50^{\circ} \mathrm{C}$. The total minutes at each temperature over the 10 -day interval is shown on the y-axis. 


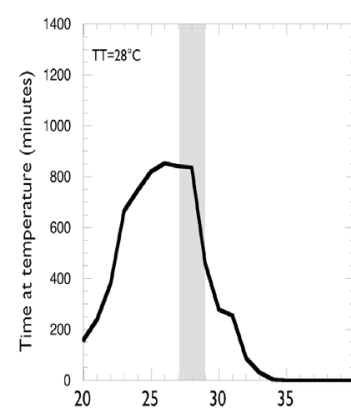

(a)

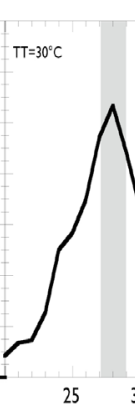

(b)

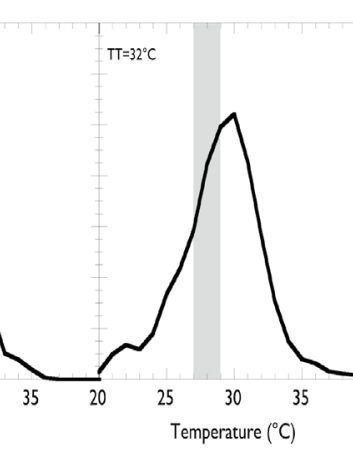

(c)

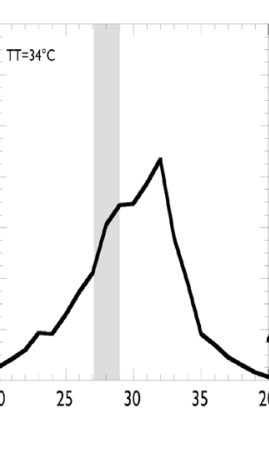

(d)

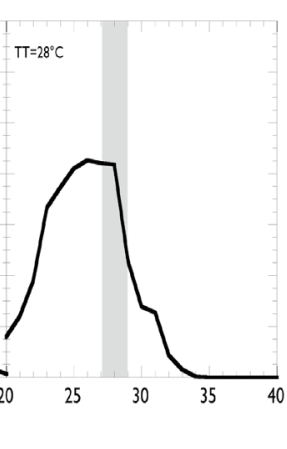

(e)

Figure 6. Demonstration of possible temperature distributions for stress management using TT irrigation. Each panel represents at 10-day period at a different TT setting designed to produce a shift in water status and canopy temperature. The grey bar indicates canopy temperatures of $28^{\circ} \mathrm{C} \pm 1{ }^{\circ} \mathrm{C}$ as an indicator of metabolic optimality. The sequence is; (a) A period at fully irrigated $\left(\mathrm{TT} 28^{\circ} \mathrm{C}\right)$; (b) A following period of low stress at thermal optimum $\left(\mathrm{TT} 30^{\circ} \mathrm{C}\right)$; (c) A period of high stress $\left(\mathrm{TT} 34^{\circ} \mathrm{C}\right)$; (d) Increased irrigation to moderate stress $\left(\mathrm{TT} 32^{\circ} \mathrm{C}\right)$ and $(\mathrm{e}) \mathrm{A}$ return to full irrigation $\left(\mathrm{TT} 28^{\circ} \mathrm{C}\right)$.

gation. Since the transpiration of the plant is variable over both the course of the day and the growing period, managed deficit irrigation will require continuous adjustment of irrigation, ideally on diurnal and seasonal timeframes. In greenhouse operations this is most often accomplished by varying the irrigation volume at a fixed time interval or alternatively by weighing pots over time and calculating transpiration for use as the basis for irrigation. Such an approach can be quite effective though it is time consuming and, if automated, relatively expensive. Canopy temperature can be remotely monitored automatically on short time intervals over the life of the plant and advances in the hardware used to measure canopy temperature have resulted in reductions in both the cost and complexity of monitoring canopy temperatures [2].

In this study, a combination of hardware and software was used to establish and manage water deficits in cotton. This was accomplished by irrigating in response to canopy temperatures that were monitored on a 1-minute interval. The use of means of 1-minute canopy temperature values coupled with a 5-minute irrigation interval provided relatively fine control. The results indicate that a canopy temperature threshold-based irrigation system that uses plant transpiration as the sensor of water status provides a mechanism for managing plant water status. Unlike irrigation systems that apply a specific volume of water on a fixed time interval, the canopy temperature-based system in this study applied a fixed volume of water on a variable time interval. Such a system incorporates water use by the plant into a feed-back loop that applies a volume of water and waits until the plant has used that before another irrigation is called for. As such it should be responsive to the size of the plant and the environmental conditions over the course of growth and development.

It is important to understand that, in this study, irrigation was fully automated and triggered only in response to alterations in canopy temperature. Aside from the choice of the temperature thresholds and the fixed irrigation volume/irrigation event, there was no human intervention over the 10-day period. The plant canopy served as the irrigation indicator and the infrared thermometer simply served to measure that indicator.

Since it uses a near-continuous canopy temperature and a 5-minute irrigation cycle, the canopy temperature stress management system will automatically correct for the over-application of water during an irrigation event. If the amount of water applied at the beginning of an irrigation cycle is not consumed by the plant over the irrigation interval, the system will delay subsequent irrigations until the water has been consumed and the canopy temperature once again exceeds the temperature threshold.

This canopy temperature stress management system was used to alter and control canopy temperatures of cotton over a 10-day period in a greenhouse. It is common knowledge that plant canopy temperatures are related to water status to such a degree that canopy temperature-based irrigation has been used for decades [6]. While irrigation management is typically used to prevent or reduce the water stress experienced by the plant, our goal was to use the timing of irrigation to establish and manage water deficits. Since management of water deficits requires an ability to identify and quantify water deficits, canopy temperature was used to identify the stress and the time thresholds were used to quantify the stress. 
The canopy temperature stress management system is most effective in limiting the occurrence of canopy temperatures above the temperature threshold and less effective at shifting canopy temperatures upward toward the temperature threshold. As the amount of water applied at each irrigation increases, the amount of time required for its consumption increases. A single irrigation volume was used for the four temperature threshold treatments in this study. This irrigation volume must be sufficient to meet the transpirational need of the plant between irrigation events. In this instance the $30 \mathrm{ml} /$ irrigation volume was used because it was the fixed irrigation volume that was previously used in the fixed-interval, fixed volume standard irrigation protocol in the greenhouse. This value could most certainly be further optimized.

The use of canopy temperature in this manner resulted in differential patterns of irrigation and canopy temperatures over time. The canopy temperatures in excess of the temperature threshold were effectively limited.

\section{Conclusion}

Canopy temperature was used to identify, quantify, and manage water deficits in the cotton in this study. Irrigation management based on temperature thresholds, near-continuous canopy temperature measurement and a feedback irrigation loop demonstrated the utility of the approach. It was shown that the total irrigation volume over the 10-day period was a function of the TT used in the irrigation. The system was reproducible to the extent that replicates of TT's produced similar patterns of irrigation and canopy temperature. The canopy temperature of the plants was a clear reflection of the TT that was used to control its irrigation.

\section{References}

[1] Hochachka, P.W. and Somero, G.N. (2002) Biochemical Adaptation. Princeton University Press, Princeton.

[2] Mahan, J.R. and Yeater, K.M. (2008) Agricultural Applications of a Low-Cost Infrared Thermometer. Computers and Electronics in Agriculture, 64, 262-267. http://dx.doi.org/10.1016/j.compag.2008.05.017

[3] Burke, J.J., Mahan, J.R. and Hatfield, J.L. (1988) Crop-Specific Thermal Kinetic Windows in Relation to Wheat and Cotton Biomass Production. Agronomy Journal, 80, 553-556. http://dx.doi.org/10.2134/agronj1988.00021962008000040001x

[4] Mahan, J., Dotray, P. and Light, G. (2004) Thermal Dependence of Enzyme Function and Inhibition; Implications for, Herbicide Efficacy and Tolerance. Physiologia Plantarum, 120, 187-195. http://dx.doi.org/10.1111/j.0031-9317.2004.0255.x

[5] Light, G.G., Dotray, P.A. and Mahan, J.R. (2001) A Thermal Application Range for Postemergence Pyrithiobac Applications. Weed Science, 49, 543-548. http://dx.doi.org/10.1614/0043-1745(2001)049[0543:ATARFP]2.0.CO;2

[6] Wanjura, D., Upchurch, D., Mahan, J. and Burke, J. (2002) Cotton Yield and Applied Water Relationships under Drip Irrigation. Agricultural Water Management, 55, 217-237. http://dx.doi.org/10.1016/S0378-3774(01)00175-5

[7] Mahan, J.R. (2000) Thermal Dependence of Malate Synthase Activity and Its Relationship to the Thermal Dependence of Seedling Emergence. Journal of Agricultural and Food Chemistry, 48, 4544-4549. http://dx.doi.org/10.1021/jf9902752

[8] Halim, R.A., Buxton, D.R., Hattendorf, M.J. and Carlson, R.E. (1989) Water-Stress Effects on Alfalfa Forage Quality after Adjustment for Maturity Differences. Agronomy Journal, 81, 189-194. http://dx.doi.org/10.2134/agronj1989.00021962008100020010x

[9] Shock, C.C., Feibert, E.B., Saunders, L.D. and Klauzer, J. (2007) Deficit Irrigation for Optimum Alfalfa Seed Yield and Quality. Agronomy Journal, 99, 992-998. http://dx.doi.org/10.2134/agronj2006.0226

[10] Pennypacker, B.W., Leath, K.T. and Hill Jr., R.R. (1991) Impact of Drought Stress on the Expression of Resistance to Verticillium albo-atrum in Alfalfa. Phytopathology, 81, 1014-1024. http://dx.doi.org/10.1094/Phyto-81-1014

[11] Carter, P.R., and Sheaffer, C.C. (1983) Alfalfa Response to Soil Water Deficits. I. Growth, Forage Quality, Yield, Water Use, and Water-Use Efficiency. Crop Science, 23, 669-675. http://dx.doi.org/10.2135/cropsci1983.0011183X002300040016x

[12] Chaves, M.M., Santos, T.P., de Souza, C.R., Ortuño, M.F., Rodrigues, M.L., Lopes, C.M., Maroco, J.P. and Pereira, J.S. (2007) Deficit Irrigation in Grapevine Improves Water-Use Efficiency While Controlling Vigour and Production Quality. Annals of Applied Biology, 150, 237-252. http://dx.doi.org/10.1111/j.1744-7348.2006.00123.x

[13] Bonada, M., Sadras, V., Moran, M. and Fuentes, S. (2013) Elevated Temperature and Water Stress Accelerate Mesocarp Cell Death and Shrivelling, and Decouple Sensory Traits in Shiraz Berries. Irrigation Science, 31, 1317-1133. http://dx.doi.org/10.1007/s00271-013-0407-z 
[14] Acevedo-Opazo, C., Ortega-Farias, S. and Fuentes, S. (2010) Effects of Grapevine (Vitis vinifera L.) Water Status on Water Consumption, Vegetative Growth and Grape Quality: An Irrigation Scheduling Application to Achieve Regulated Deficit Irrigation. Agricultural Water Management, 97, 956-964. http://dx.doi.org/10.1016/j.agwat.2010.01.025

[15] Gómez-Rico, A., Salvador, M.D., Moriana, A., Pérez, D., Olmedilla, N., Ribas, F. and Fregapane, G. (2007) Influence of Different Irrigation Strategies in a Traditional Cornicabra cv. Olive Orchard on Virgin Olive Oil Composition and Quality. Food Chemistry, 100, 568-578. http://dx.doi.org/10.1016/j.foodchem.2005.09.075

[16] Moriana, A., Perez-Lopez, D., Gómez-Rico, A., de los Desamparados Salvador, M., Olmedilla, N., Ribas, F. and Fregapane, G. (2007) Irrigation Scheduling for Traditional, Low-Density Olive Orchards: Water Relations and Influence on Oil Characteristics. Agricultural Water Management, 87, 171-179. http://dx.doi.org/10.1016/j.agwat.2006.06.017

[17] Agam, N., Cohen, Y., Berni, J.A.J., Alchanatis, V., Kool, D., Dag, A., Yermiyahu, U. and Ben-Gal, A. (2013) An Insight to the Performance of Crop Water Stress Index for Olive Trees. Agricultural Water Management, 118, 79-86. http://dx.doi.org/10.1016/j.agwat.2012.12.004

[18] Dag, A., Ben-Gal, A., Yermiyahu, U., Basheer, L., Nir, Y. and Kerem, Z. (2008) The Effect of Irrigation Level and Harvest Mechanization on Virgin Olive Oil Quality in a Traditional Rain-Fed "Souri” Olive Orchard Converted to Irrigation. Journal of the Science of Food and Agriculture, 88, 1524-1528. http://dx.doi.org/10.1002/jsfa.3243 
Scientific Research Publishing (SCIRP) is one of the largest Open Access journal publishers. It is currently publishing more than 200 open access, online, peer-reviewed journals covering a wide range of academic disciplines. SCIRP serves the worldwide academic communities and contributes to the progress and application of science with its publication.

Other selected journals from SCIRP are listed as below. Submit your manuscript to us via either submit@scirp.org or Online Submission Portal.
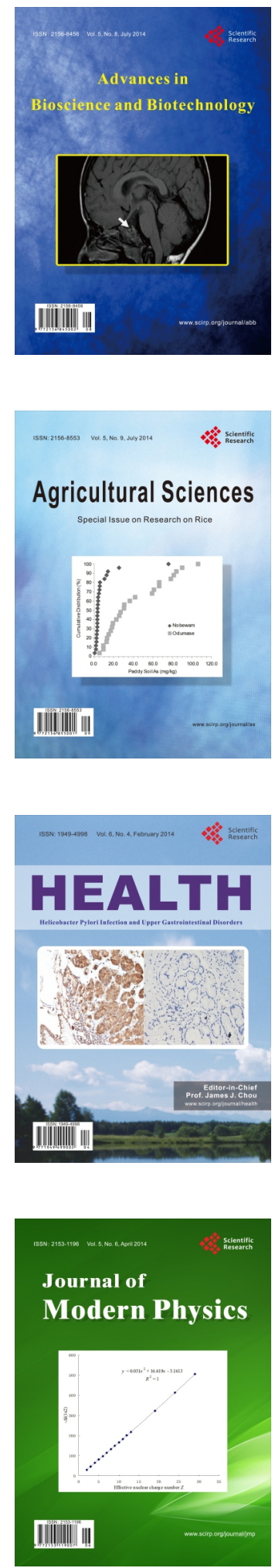
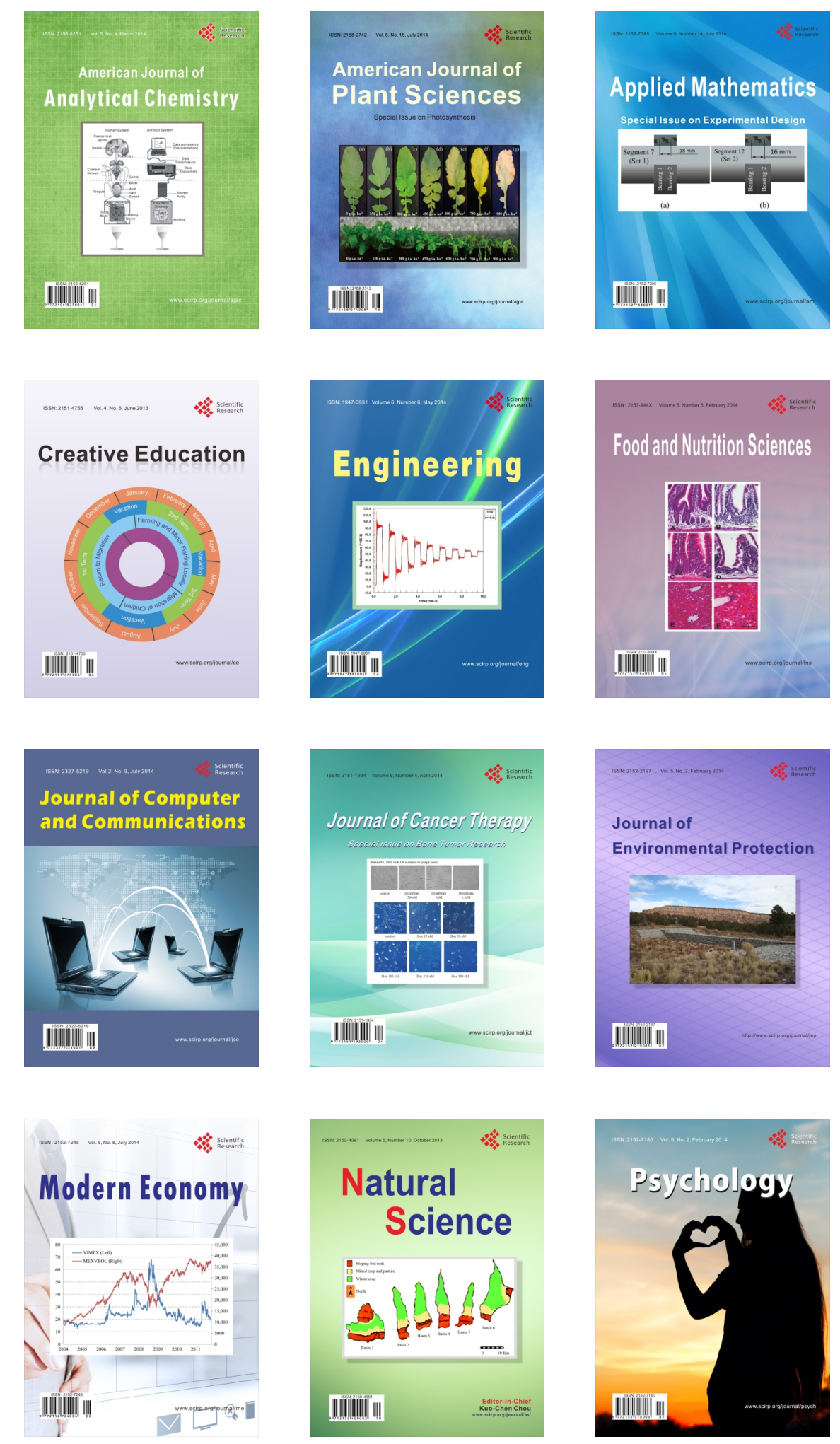